\title{
Compressive Behavior and Mechanical Characteristics and Their Application to Stress-Strain Relationship of Steel Fiber-Reinforced Reactive Powder Concrete
}

\author{
Baek-Il Bae, ${ }^{1}$ Hyun-Ki Choi, ${ }^{2}$ Bong-Seop Lee, ${ }^{2}$ and Chang-Hoon Bang ${ }^{2}$ \\ ${ }^{1}$ Research Institute of Industrial Science, Hanyang University, 17 Haengdang-Dong, Seongdong-Gu, Seoul 04763, Republic of Korea \\ ${ }^{2}$ Department of Fire and Disaster Prevention Engineering, Kyungnam University, Gyeongsangnam-do 51767, Republic of Korea
}

Correspondence should be addressed to Hyun-Ki Choi; chk7796@kyungnam.ac.kr

Received 21 April 2016; Revised 26 May 2016; Accepted 7 June 2016

Academic Editor: Juan J. Del Coz Díaz

Copyright (C) 2016 Baek-Il Bae et al. This is an open access article distributed under the Creative Commons Attribution License, which permits unrestricted use, distribution, and reproduction in any medium, provided the original work is properly cited.

\begin{abstract}
Although mechanical properties of concrete under uniaxial compression are important to design concrete structure, current design codes or other empirical equations have clear limitation on the prediction of mechanical properties. Various types of fiber-reinforced reactive powder concrete matrix were tested for making more usable and accurate estimation equations for mechanical properties for ultra high strength concrete. Investigated matrix has compressive strength ranged from $30 \mathrm{MPa}$ to $200 \mathrm{MPa}$. Ultra high strength concrete was made by means of reactive powder concrete. Preventing brittle failure of this type of matrix, steel fibers were used. The volume fraction of steel fiber ranged from 0 to $2 \%$. From the test results, steel fibers significantly increase the ductility, strength and stiffness of ultra high strength matrix. They are quantified with previously conducted researches about material properties of concrete under uniaxial loading. Applicability of estimation equations for mechanical properties of concrete was evaluated with test results of this study. From the evaluation, regression analysis was carried out, and new estimation equations were proposed. And these proposed equations were applied into stress-strain relation which was developed by previous research. Ascending part, which was affected by proposed equations of this study directly, well fitted into experimental results.
\end{abstract}

\section{Introduction}

The compressive strength of concrete is an important parameter in the design of reinforced concrete structures according to current design criteria [1]. In recent years, performancebased designs have been increasingly used, with accompanying increases in the diversity of types and strengths of concrete and reinforcement used. As a result, prediction of the compressive strength and other mechanical properties of concrete have become important to use various types of materials, because these parameters control the stress-strain behavior of concrete. The concrete stress-strain models developed in previous studies [2-11] and used extensively are based on coefficients determined from experiments. These stressstrain relations cannot be used without additional investigation because many coefficients for stress-strain relation of concrete are determined by limited number of experiments. The reason for this is that there are limits to the strength ranges to which such models are applicable, depending on the conditions of the tests conducted to develop these models. Therefore, an equation for use in estimating the mechanical properties of ultrahigh strength fiber-reinforced concrete was derived. These equations can serve as a basis for describing the stress-strain relationships for such materials, even beyond the limits of the currently used empirical formulas or code provisions.

Usually, normal strength concrete members are designed using rectangular stress block parameters under flexure. Current design codes provide the rectangular stress block parameters for simplified design methodology. However, these stress blocks are semiempirical parameters. They are determined by tests of reinforced concrete columns and they have apparent limitations. Rectangular stress block can be used because the shape of stress-strain relation of concrete is similar to the trapezoid. However, shape of stress-strain relationship of concrete changed into triangle as increase of 
TABLE 1: Mix proportions.

\begin{tabular}{|c|c|c|c|c|c|c|c|c|c|}
\hline \multirow{2}{*}{ ID } & \multirow{2}{*}{$\mathrm{w} / \mathrm{b}$} & \multicolumn{7}{|c|}{ Weight $\left(\mathrm{kg} / \mathrm{m}^{3}\right)$} & \multirow{2}{*}{$\begin{array}{c}f_{c k} \\
{[\mathrm{MPa}}\end{array}$} \\
\hline & & Cement & Water & Silica fume & Sand & Filler & Steel fiber ${ }^{* *}$ & Super-plasticizer & \\
\hline $30-0$ and $f$ series* & $0.43^{\dagger}$ & 344 & 172 & - & 635 & $1180^{\dagger \dagger}$ & $0,37,74,147$ & 0.0 & 30 \\
\hline $80-0$ and $f$ series ${ }^{*}$ & 0.30 & 780 & 255 & 60 & 1097 & 114 & $0,37,74,147$ & 0.5 & 80 \\
\hline $100-0$ and $f$ series & 0.25 & 809 & 222 & 80 & 1052 & 162 & $0,37,74,147$ & 1 & 100 \\
\hline $150-0$ and $\mathrm{f}$ series & 0.20 & 820 & 190 & 112 & 918 & 186 & $0,37,74,147$ & 1.04 & 150 \\
\hline $200-0$ and $f$ series & 0.17 & 830 & 176 & 207 & 912 & 246 & $0,37,74,147$ & 1.08 & 200 \\
\hline
\end{tabular}

${ }^{*} \mathrm{f}$ series means fiber-reinforced mix.

** 0 means no fiber, 37 for $0.5 \%$ volume fraction of fiber contents, 74 means $1 \%$ volume fraction of fiber contents, and 147 means $2 \%$ volume fraction of fiber contents.

${ }^{\dagger}$ Water-cement ratio was used for normal strength concrete.

${ }^{\dagger \dagger}$ Coarse aggregates were used for normal strength concrete.

compressive strength of concrete. For this reason, rectangular stress block parameters depend on the compressive strength of concrete. For the compressive strength of concrete, higher than $76 \mathrm{MPa}$, rectangular stress block parameters $\alpha_{1}$ and $\beta_{1}$ of ACI318 [1] are limited by 0.85 and 0.65 , respectively. However, in this case, relation between ultimate strain of concrete and peak stress should be checked again. Because high strength concrete failed with brittle manner usually, they cannot experience the slight and gradual decrease of compressive stress. It may cause the unexpected failure under flexure, especially for ultrahigh strength concrete member.

Making brittle and unexpected failure of ultrahigh strength concrete matrix under compression more ductile, steel fiber can be included in the matrix. Inclusion of steel fiber can change explosive failure of ultrahigh strength concrete and provide more tensile strength and deformability [12]. So steel fiber can usually be used for ultrahigh strength concrete matrix.

Ultrahigh performance concrete usually has much higher compressive strength and tensile strength than normal strength concrete $[13,14]$. Shape of stress distribution under compression and effect of tensile strength of concrete shall be considered in design of section. Many related design guidelines were suggested the design methodologies for ultra high performance concrete flexural member but their safety should be investigated and more easy way to design the section shall be found. Therefore, in this study, various types of stress block and distribution combinations were evaluated with experimental result and previous research results.

\section{Compression Testing of Ultrahigh Strength Steel Fiber-Reinforced Concrete}

In this study, compression tests of cylindrical concrete specimens with compressive strengths in the range of 30-200 MPa were carried out to derive equations that can be safely used to estimate the mechanical properties of concrete even beyond the strength limits given in the design criteria. The test results were analyzed to determine the stress-strain relationship of concrete over a range of design concrete strengths and compare the relationship to others described by existing equations. The important mechanical properties related to the stress-strain relationship of concrete under compressive loading that were considered in this study were the elastic modulus, the stress-to-matrix strength ratio, and the strain at the maximum stress.

2.1. Experiment Design. According to the previous researches on mechanical properties of concrete and fiber-reinforced concrete [2-11], the mechanical properties that determine the stress-strain relationship of fiber-reinforced concrete depend on the proportion of fibers contents and matrix strength of concrete. Therefore, the compressive strength of the concrete matrix and the contents of steel fiber are important parameters in this study. The compressive strength range considered was $30-200 \mathrm{MPa}$. Because it is hard to make compressive strength exceeding $100 \mathrm{MPa}$, we use reactive powder concrete (RPC) as steel fiber-reinforced concrete matrix.

Steel fibers were mixed into concrete batches at volumetric ratios of $0.5 \%$ to $2 \%$ to ensure both improvement of the structural performance of the concrete and workability of the concrete after addition of the fibers. Five cylindrical specimens $(\varphi 100 \times 200 \mathrm{~mm}$ in size $)$ were produced for each mix. Loading was performed using KS F 2405 [15]. The strain rate of the specimen was measured using a compressor meter. Table 1 lists the mixes used in the testing.

\subsection{Experimental Results for the Mechanical Properties of Steel} Fiber-Reinforced Reactive Powder Concrete. Figure 1 shows typical stress-strain relation of steel fiber-reinforced powder concrete cylinder specimens. According to Figure 1, steel fiber can increase ductility and strength of brittle matrix. Therefore, the most important investigation shall be the increase rate of ductility and strength of matrix according to the inclusion of steel fiber. So we listed the test results for the elastic modulus, the maximum stress, and the strain at the maximum stress which show the ductility and strength of material in Table 2.

The values shown are the average values for the five specimens from each mix. The test results indicate that steel fiber significantly affects the properties related to the ductility of material. Figure 2 shows the trends in the parameters of elastic modulus and strain at peak strength with respect to the steel fiber content.

The mixes with design strengths of $30,80,100,150$, and $200 \mathrm{MPa}$ that were reinforced with fibers at a volume 
TABLE 2: Test results (mean value of test specimens).

\begin{tabular}{|c|c|c|c|c|}
\hline ID & $\begin{array}{c}V_{f} \\
{[\%]}\end{array}$ & $\begin{array}{c}E_{c} \\
{[\mathrm{MPa}]}\end{array}$ & $\begin{array}{c}f_{c o} \\
{[\mathrm{MPa}]}\end{array}$ & $\begin{array}{c}\mathcal{E}_{c o} \\
{[\% \mathrm{o}]}\end{array}$ \\
\hline C $30-0$ & 0 & 26,756 & 32.54 & 2.65 \\
\hline $\mathrm{C} 30-\mathrm{f} 0.5$ & 0.5 & 27,659 & 33.32 & 2.98 \\
\hline C30-f1.0 & 1.0 & 28,751 & 34.72 & 3.32 \\
\hline $\mathrm{C} 30-\mathrm{f} 2.0$ & 2.0 & 31,221 & 34.98 & 3.43 \\
\hline C80-0 & 0 & 32,970 & 80.79 & 3.16 \\
\hline C80-f0.5 & 0.5 & 33,597 & 82.60 & 3.55 \\
\hline C80-f1.0 & 1.0 & 34,097 & 85.17 & 3.64 \\
\hline $\mathrm{C} 80-\mathrm{f} 2.0$ & 2.0 & 34,768 & 89.01 & 4.04 \\
\hline $\mathrm{C} 100-\mathrm{f} 0$ & 0 & 36,233 & 104.86 & 3.39 \\
\hline C100-f0.5 & 0.5 & 37,376 & 107.39 & 3.71 \\
\hline C100-f1.0 & 1.0 & 38,732 & 111.93 & 3.95 \\
\hline $\mathrm{C} 100-\mathrm{f} 2.0$ & 2.0 & 38,099 & 116.92 & 4.09 \\
\hline C150-0 & 0 & 42,023 & 149.40 & 3.97 \\
\hline C150-f0.5 & 0.5 & 41,203 & 154.96 & 4.47 \\
\hline C150-f1.0 & 1.0 & 42,365 & 159.60 & 4.77 \\
\hline $\mathrm{C} 150-\mathfrak{f} 2.0$ & 2.0 & 43,222 & 162.40 & 4.79 \\
\hline C200-0 & 0 & 45,512 & 198.21 & 4.87 \\
\hline C200-f0.5 & 0.5 & 45,019 & 202.70 & 4.97 \\
\hline C200-f1.0 & 1.0 & 46,734 & 210.40 & 5.26 \\
\hline $\mathrm{C} 200-\mathrm{f} 2.0$ & 2.0 & 47,515 & 216.52 & 5.39 \\
\hline
\end{tabular}

$V_{f}$ : volume fraction of steel fiber (\%), $E_{c}$ : elastic modulus (MPa), $f_{c o}$ : compressive strength of concrete (tested value, $\mathrm{MPa}$ ), $\varepsilon_{c o}$ : strain corresponding peak stress.

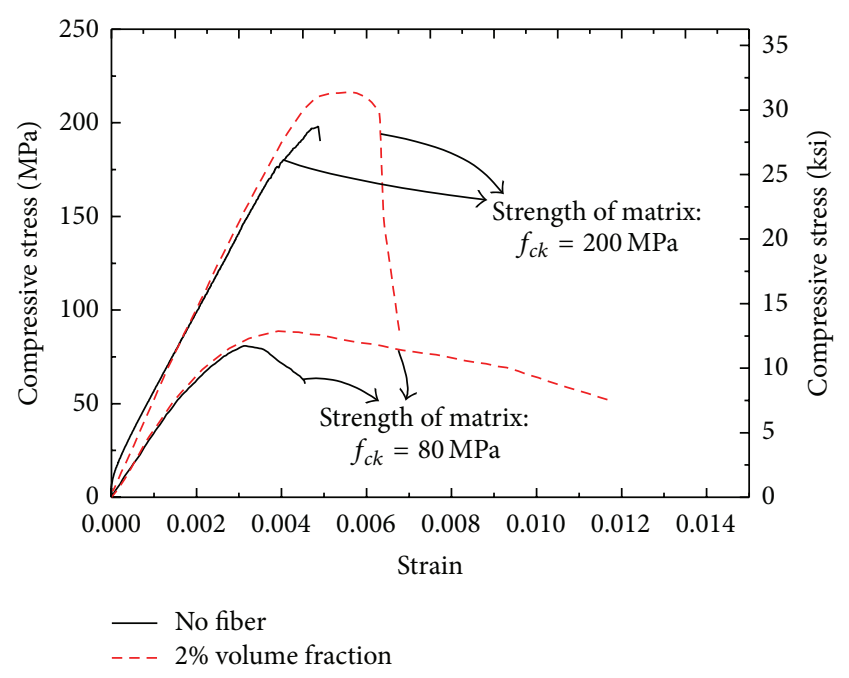

FIGURE 1: Typical uniaxial compressive stress-strain relation of steel fiber-reinforced powder reactive concrete.

of $2 \%$ exhibited compressive strength increases of $7.5 \%$, $10.2 \%, 11.5 \%, 8.7 \%$, and $9.2 \%$, respectively. The strains at the maximum stress increased by $29.4 \%, 27.8 \%, 23.5 \%, 20.6 \%$, and $10.6 \%$, respectively, with $2 \%$ fiber volume fraction. The increases of strain at peak stress are significant in comparison to the increases in strength. Significant increase of strain at peak stress would be caused by the confinement effect of steel fiber to the formation of cracks along the specimen axis, as shown in Figure 3, the failure aspects of fiber-reinforced specimen.

This reinforcing effect on the strain at peak stress was shown in all the cases of compressive strength of matrix. However, the ductility increase of the concrete specimens with strengths greater than $100 \mathrm{MPa}$ was smaller than the increase of the ductility of the 30 and $80 \mathrm{MPa}$ concrete. That is, at higher compressive strengths, the effect of reinforcing effect of steel fibers on improving the ductility decreases.

\section{Estimation of the Mechanical Properties of Steel Fiber-Reinforced Reactive Powder Concrete}

We collected concrete material test results from a number of studies [30-44] and analyzed them together with the test results obtained in this study to estimate the important parameters needed to derive a stress-strain relationship that can be easily applied over a wider range of concrete strengths than the range encompassed by previous studies. The data collected included 295 results for compressive strength increase, 134 results for the strain at the maximum stress, and 1486 results for the elastic modulus. In this study, the reinforcing effect of the fiber was characterized using a reinforcing index (RI) associated with the aspect ratio and other physical properties of the fiber. The value of RI for a particular type of fiber is determined using (1). The aspect ratio of the fibers, the fiber end shape, and the amount of fiber reinforcement are important parameters in this equation. Consider

$$
\mathrm{RI}=\frac{V_{f} L_{f} d_{f}}{D_{f}},
$$

where RI is reinforcing index, $V_{f}$ is volume fraction of steel fiber, $L_{f}$ is length of steel fiber, and $D_{f}$ is diameter of steel fiber.

The term $d_{f}$ in (1) is a correction factor for the end shape of the fiber. In this study, we used correction factors of 1 , 2.0, and 1.5 for straight fibers, hooked fibers, and crimped fibers, respectively, to correct for the effect of fiber shape, as suggested in the literature [45].

In order to compare the proposed estimation methods and find the important parameters on mechanical characteristics on steel fiber-reinforced reactive powder concrete we also collect the empirical equations about mechanical characteristic estimation equations for concrete under uniaxial compression.

Table 3 shows an equation for estimating the strain at the maximum stress as a function of the reinforcing effect of the steel fibers and the compressive strength of the concrete. Table 4 shows an equation for estimating the elastic modulus. When examining equations about compressive mechanical characteristics on concrete and fiber-reinforced concrete, the most important parameter is compressive strength of concrete and (1), reinforcing index. Most of the equations consider the effect of steel fiber as additional value independent of compressive strength of concrete. However, as 


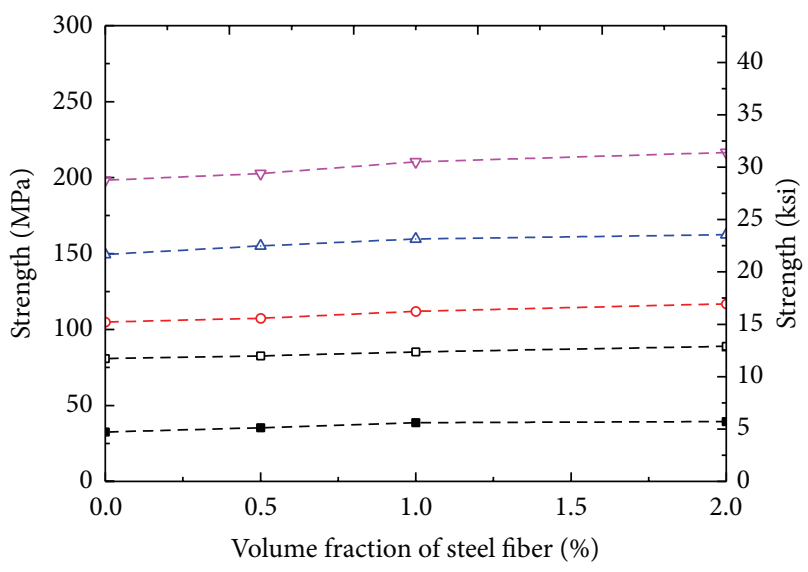

- - Matrix type: $30 \mathrm{MPa}$

- - Matrix type: $80 \mathrm{MPa}$

-o- Matrix type: $100 \mathrm{MPa}$

(a) Compressive strength

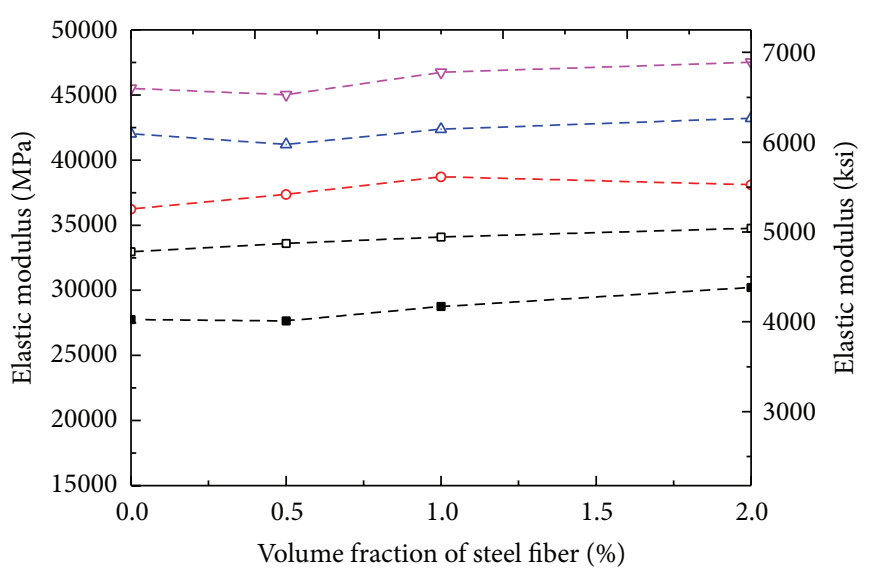

- - Matrix type: $30 \mathrm{MPa} \quad$ - $\_$- Matrix type: $150 \mathrm{MPa}$

- - Matrix type: $80 \mathrm{MPa} \quad-\nabla-$ Matrix type: $200 \mathrm{MPa}$

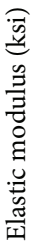

(b) Elastic modulus

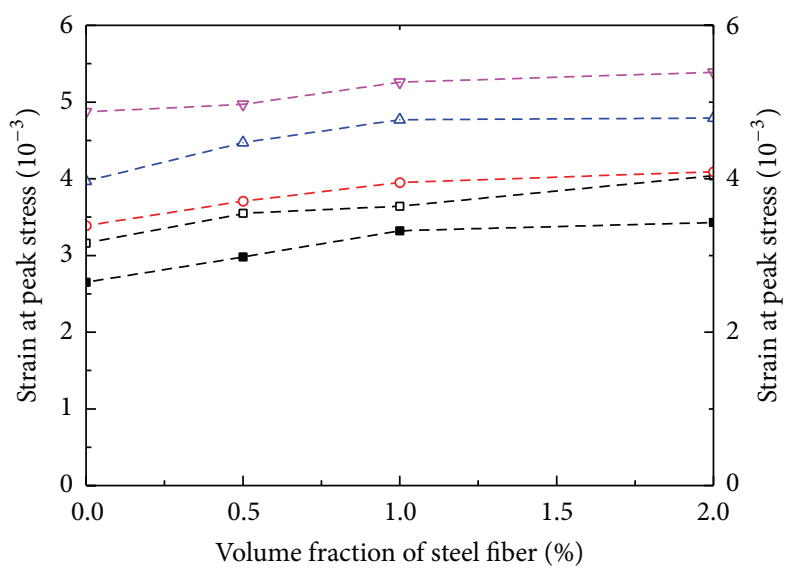

$\begin{array}{ll}\text {-- } \text { - Matrix type: } 30 \mathrm{MPa} & -\triangle \text { - Matrix type: } 150 \mathrm{MPa} \\ \text { - - Matrix type: } 80 \mathrm{MPa} & -\nabla \text { - Matrix type: } 200 \mathrm{MPa} \\ \text { - } \text { - Matrix type: } 100 \mathrm{MPa} & \end{array}$

(c) Strain at peak stress

FIGURE 2: Mechanical characteristics of fiber-reinforced reactive powder concrete under uniaxial compression.

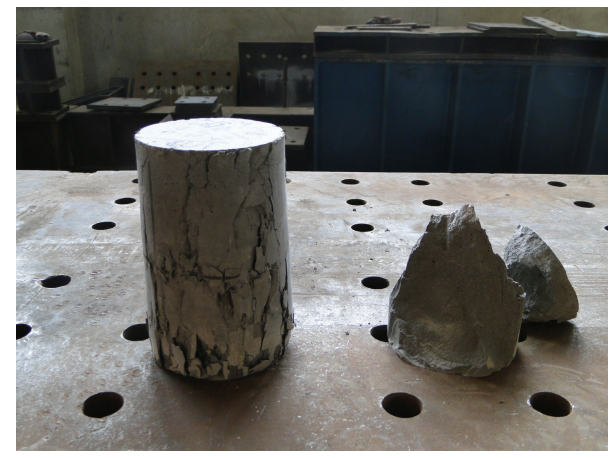

FIGURE 3: Failure of specimens under uniaxial compression.

shown in test results, increase rate of mechanical properties of steel fiber-reinforced reactive powder concrete is affected by compressive strength of concrete. In this section we quantify the increase rate of mechanical properties of concrete considering combination of compressive strength of matrix and steel fiber contents.

3.1. Mechanical Properties of Reactive Powder Concrete Matrix. For fiber-reinforced concrete, the elastic modulus and the strain at the maximum stress are often determined from equations that are based on test results for nonreinforced mixes. The accuracy of such estimates is significantly affected by the strength ranges of the specimens used to derive the equations. Elastic modulus and $\varepsilon_{c o}$ values derived from the results of material testing conducted in previous studies [3044] and in the present study are shown in Figures 4 and 5, respectively. The associated equations are also shown. Tables 5 and 6 list the statistical parameters of the equations.

As shown in Table 5 and Figure 4, the current code provisions show the highest accuracy in the estimation of the 
TABLE 3: Prediction equations for strain at peak stress (previous researches).

\begin{tabular}{|c|c|c|}
\hline Researcher & $\begin{array}{c}\text { Equation } \\
\end{array}$ & Limitation $[\mathrm{MPa}]$ \\
\hline Collins et al. [6] & $\varepsilon_{c o}=\frac{f_{c k}}{E_{c}} \frac{n}{n-1}, \quad n=0.8+\frac{f_{c k}}{17}, E_{c}=3320 f_{c k}^{0.5}+6900$ & $f_{c k} \leq 100$ \\
\hline Wee et al. [7] & $\varepsilon_{c o}=\frac{180\left(f_{c k}\right)^{0.25}}{10^{6}}$ & $f_{c k} \leq 120$ \\
\hline Ros [16] & $\varepsilon_{c o}=\frac{\left(0.0546+0.003713 f_{c k}\right)}{100}$ & $f_{c k} \leq 43$ \\
\hline Fafitis and Shah [17] & $\varepsilon_{c o}=1.491 \times 10^{-5} f_{c k}+0.00195$ & $f_{c k} \leq 66$ \\
\hline De Nicolo et al. [18] & $\varepsilon_{c o}=0.00076+\left[\left(0.626 f_{c k}-4.33\right) \times 10^{-7}\right]^{0.5}$ & $f_{c k} \leq 90$ \\
\hline CEB-fip 228 [9] & $\varepsilon_{c o}=\frac{0.7\left(f_{c k}\right)^{0.11}}{1000}$ & $f_{c k} \leq 100$ \\
\hline EC2 [19] & $\varepsilon_{c o}=\frac{\left(2.0+0.085\left(f_{c k}-50\right)^{0 . J}\right)}{1000}, \quad$ for $f_{c k} \geq 50 \mathrm{MPa}$; otherwise $\varepsilon_{c o}=0.002$ & $f_{c k} \leq 90$ \\
\hline Soroushian and Lee [20] & $\varepsilon_{c o f}=0.007 \mathrm{RI}+0.0021, \quad \mathrm{RI}=\frac{v_{f} L_{f}}{D_{f}}$ & - \\
\hline Nataraja et al. [21] & $\varepsilon_{c o f}=0.002+0.006(\mathrm{RI}), \quad \mathrm{RI}=\frac{W_{f} L_{f}}{D_{f}}$ & $f_{c k} \leq 50$ \\
\hline Dhakal et al. [22] & $\varepsilon_{c o f}=0.002+2000 \alpha_{c} V_{f}^{2}, \quad \alpha_{f}=1.0$ (flat), $\alpha_{f}=2.4$ (hooked) & $f_{c k} \leq 40$ \\
\hline
\end{tabular}

$E_{c}$ : secant elastic modulus of concrete at $0.45 f_{c k}(\mathrm{MPa}), \varepsilon_{c o}$ : strain corresponding to peak stress (normal concrete), $f_{c k}$ : compressive strength of concrete (MPa), RI: reinforcing index, $D_{f}$ : diameter of steel fiber $(\mathrm{mm}), L_{f}$ : length of steel fiber $(\mathrm{mm}), V_{f}$ : volume fraction of steel fiber, $W_{f}$ : weight fraction of steel fiber.

TABLE 4: Prediction equations for modulus of elasticity (previous researches).

\begin{tabular}{|c|c|c|}
\hline Researcher & Equation & Limitation \\
\hline KCI2007 [23] & $\begin{array}{c}E_{c}=8,500 \sqrt[3]{f_{c u}}, \quad E_{c}=0.077 w_{c}^{1.5} \sqrt[3]{f_{c u}}, \quad f_{c u}=f_{c k}+8 \\
E_{c}=8,500 \sqrt[3]{f_{c u}}, \quad E_{c}=0.077 w_{c}^{1.5} \sqrt[3]{f_{c u}}, \quad f_{c u}=f_{c k}+\Delta f, \text { where } \\
\Delta f=4 \text { when } f_{c k} \leq 40 \mathrm{MPa} \text { and } \Delta f=6 \text { when } f_{c k}>60 \mathrm{MPa} . \\
\text { Interpolate between } 40 \mathrm{MPa} \text { and } 60 \mathrm{MPa}\end{array}$ & $\begin{array}{l}\text { Did not specify but } \sqrt{f_{c k}} \\
\text { cannot exceed } 8.4 \mathrm{MPa}\end{array}$ \\
\hline ACI318-11 [1] & $E_{c}=4,700 \sqrt{f_{c k}}$ (normal weight concrete), $\quad E_{c}=w_{c}^{1.5} 0.043 \sqrt{f_{c k}}$ & \\
\hline CEB-fip 228 [9] & $E_{c i}=E_{c o}\left[\frac{\left(f_{c k}+\Delta f\right)}{f_{c m o}}\right]^{1 / 3}, \Delta f=8, f_{c m o}=10, E_{c o}=22 \mathrm{GPa}$ & $f_{c k} \leq 90$ \\
\hline Martinez et al. [25] & $E_{c}=3,320 \sqrt{f_{c k}}+6,900$ & $21 \mathrm{MPa}<f_{c k}<83 \mathrm{MPa}$ \\
\hline Cook $[26]$ & $E_{c}=3.385 \times 10^{-5} w_{c}^{2.55}\left(f_{c k}\right)^{0.315}$ & - \\
\hline Ahmad and Shah [27] & $E_{c}=3.385 \times 10^{-5} w_{c}^{2.55}\left(f_{c k}\right)^{0.325}$ & $f_{c k}<84 \mathrm{MPa}$ \\
\hline Graybeal [11] & $E_{c}=3,840 \sqrt{f_{c k}}$ & $f_{c k}<200 \mathrm{MPa}$ \\
\hline Gao et al. [28] & $E_{c f}=E_{c}(1+0.173(\mathrm{RI}))$ & $70 \mathrm{MPa}<f_{c k}<85 \mathrm{MPa}$ \\
\hline Padmarajaiah [29] & $E_{c f}=E_{c}+2440(\mathrm{RI})$ & $f_{c k}<69 \mathrm{MPa}$ \\
\hline
\end{tabular}

$E_{c}$ : secant elastic modulus of concrete at $0.45 f_{c k}(\mathrm{MPa}), w_{c}$ : unit weight of concrete $\left(\mathrm{kg} / \mathrm{m}^{3}\right), f_{c k}$ : compressive strength of concrete (MPa), RI: reinforcing index, $\mathrm{RI}=V_{f} L_{f} / D_{f}$.

elastic modulus. As shown in statistical values for KCI2012, current Korean design code provision, a standard deviation is not the lowest among other estimation methods.

However, mean value, coefficient of variation, and IAE (integrated absolute error) values for KCI2012 have lowest value among other prediction methods. In general, the estimation equation for the elastic modulus tends to underestimate the modulus of elasticity for normal strength concrete and overestimate the modulus of elasticity for high strength concrete. However, highest accuracy of KCI2012 occurs because the estimation equation was developed to provide relatively safe estimates for both normal strength and high strength concrete, using different value of $\Delta f$ according to the compressive strength of concrete. Therefore, even for an ultrahigh strength concrete, there should be no significant problems associated with using the estimation equation presented in the current design standards to estimate the elastic modulus of the concrete.

Because $\varepsilon_{c o}$, the strain at the maximum stress, is an important boundary condition in defining the stress-strain relationship and important design parameter, we also compared the results of previous studies and the results of this study with respect to this parameter. In previous studies on the stress-strain relationship of concrete, the typical value used for the strain at the maximum stress is 0.002 . However, Figure 5 confirms that the strain at the maximum stress tends to increase with the compressive strength of the concrete. It was confirmed that equations from previous studies for estimation of $\varepsilon_{c o}$, which take the form of an exponential function of the compressive strength, underestimate the 


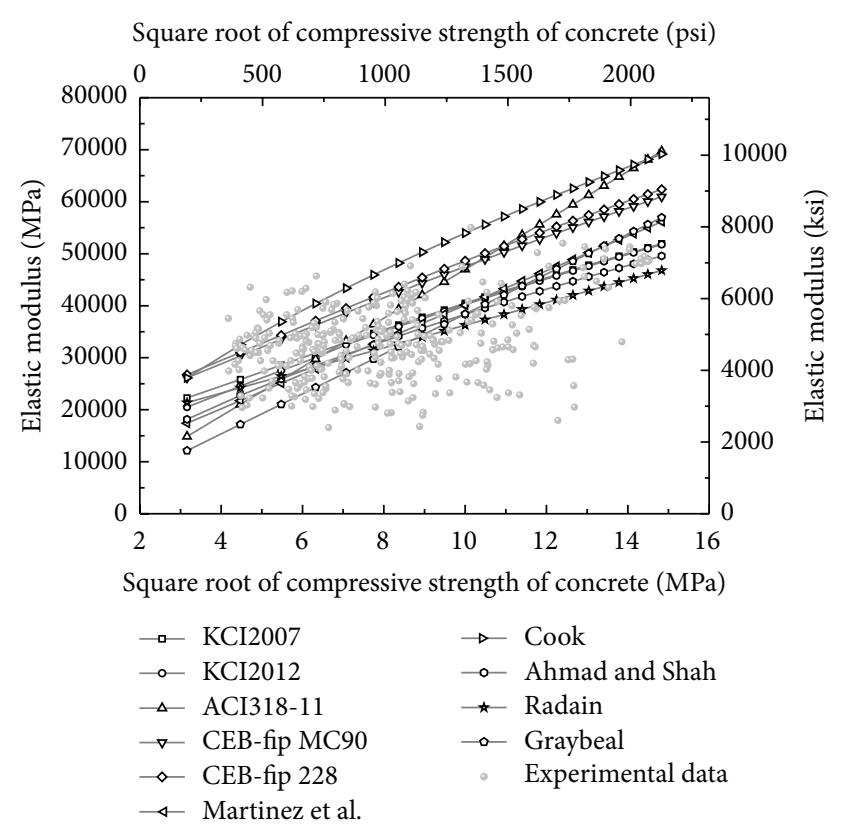

FIGURE 4: Elastic modulus: test results and prediction equations.

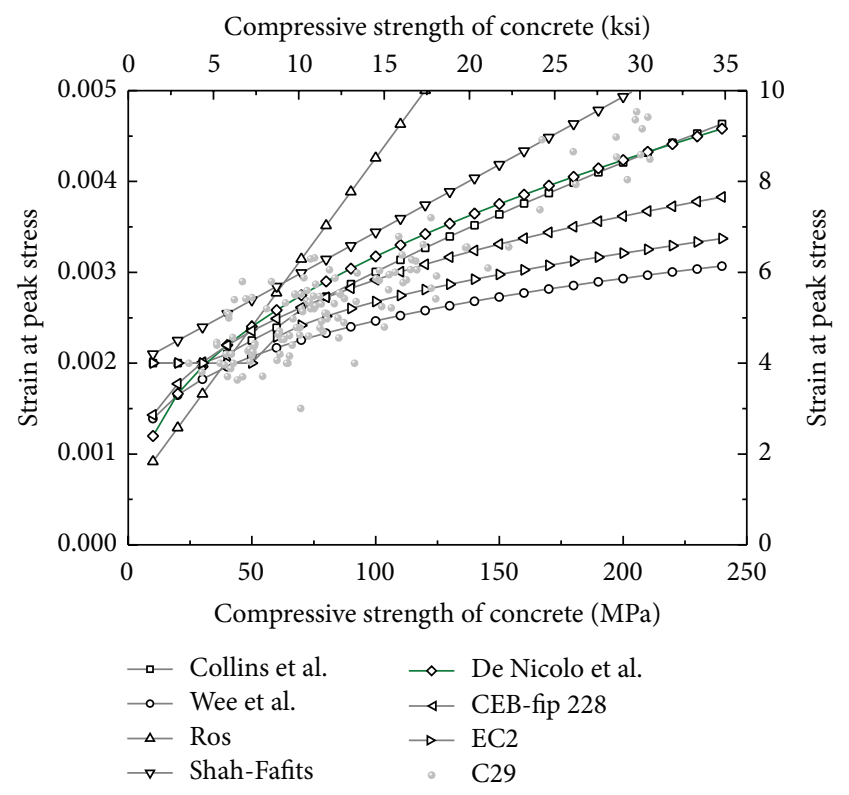

FIGURE 5: Strain at peak stress: test results and prediction equations.

increase in $\varepsilon_{c o}$ with increasing compressive strength. Table 6 confirms that the accuracy of these equations increases as the compressive strength range considered increases. Given that the equation proposed by Collins et al. [6] has the lowest IAE and average value, Collins et al. [6] equation for $\varepsilon_{c o}$ was concluded to be suitable for use with high strength mixes. Collins et al. [6] equation, shown in Table 1, reflects the effect of the elastic modulus. Because our analysis confirmed that the equation presented in the current design standards yields the highest accuracy in the estimation of the elastic modulus, this equation was used with Collins et al. [6] equation to
TABLE 5: Statistics on the prediction methods for modulus of elasticity.

\begin{tabular}{lcccc}
\hline Researcher & Mean & SD & CV & IAE \\
\hline KCI2007 [23] & 0.99 & 0.12 & 0.12 & 8.52 \\
KCI2012 [24] & 1.01 & 0.12 & 0.12 & 8.42 \\
ACI318-11 [1] & 0.93 & 0.13 & 0.14 & 13.72 \\
CEB-fip 228 [9] & 0.83 & 0.10 & 0.12 & 20.65 \\
Martinez et al. [25] & 1.05 & 0.13 & 0.12 & 9.45 \\
Cook [26] & 0.75 & 0.09 & 0.12 & 32.44 \\
Ahmad and Shah [27] & 1.07 & 0.12 & 0.12 & 9.83 \\
Graybeal [11] & 1.14 & 0.16 & 0.14 & 13.54 \\
\hline
\end{tabular}

SD: standard deviation, CV: coefficient of variation, IAE: integrated absolute error (\%).

TABLE 6: Statistics on the prediction methods for strain at peak stress under uniaxial compression.

\begin{tabular}{lcccc}
\hline Researcher & Mean & SD & CV & IAE (\%) \\
\hline Collins et al. [6] & 0.99 & 0.12 & 0.12 & 8.74 \\
Wee et al. [7] & 1.16 & 0.17 & 0.15 & 16.37 \\
Ros [16] & 0.78 & 0.19 & 0.25 & 42.04 \\
Fafitis and Shah [17] & 0.84 & 0.09 & 0.11 & 19.49 \\
De Nicolo et al. [18] & 0.93 & 0.11 & 0.12 & 11.58 \\
CEB-fip 228 [9] & 0.99 & 0.13 & 0.13 & 10.56 \\
EC2 [19] & 1.09 & 0.15 & 0.14 & 12.52 \\
\hline
\end{tabular}

SD: standard deviation, CV: coefficient of variation, IAE: integrated absolute error (\%).

estimate $\varepsilon_{c o}$. As a result, the IAE decreased by $8.67 \%$, and the average of the ratios of experimental values to estimated values was found to be 1.02 , indicating that the estimated values were on the safe side.

3.2. Effect of Steel Fiber Contents on Compressive Strength Increase. Figure 6 shows test results from previous studies [30-44] and from this study on the effect of the steel fiber contents on the increase in concrete compressive. The increase of maximum stress of test results was expressed as the ratio of the compressive strength of fiber-reinforced specimens to the compressive strength of non-fiber-reinforced specimens. The average compressive strength increase due to fiber reinforcement was $9.7 \%$. However, for specimens of the same design compressive strength, the compressive strength tended to increase linearly with increasing proportions of fiber. Examination of the results classified by the design compressive strength of the concrete indicated that the increase achieved in compressive strength with increasing fiber content tended to decrease with increasing design compressive strength. However, it is difficult to confirm that a clear correlation exists because of the high degree of variation in the test results. In particular, the correlation between compressive strength increase and fiber content tended to decrease with increasing design compressive strength. The results of our study suggest that the increases achieved in compressive strength with increasing fiber content were comparable over the range of 


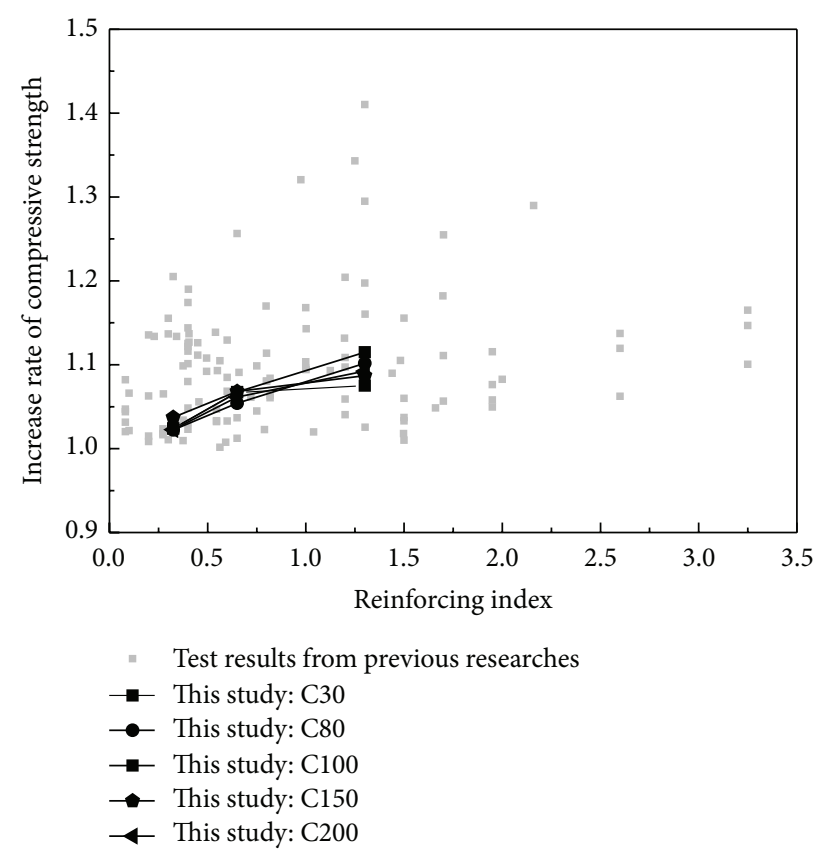

FIGURE 6: Compressive strength increase rate according to reinforcing index.

compressive strengths considered. A maximum compressive strength increase of $10 \%$ was verified.

\subsection{Effect of Steel Fiber Contents on Strain at Peak Stress.} Figure 7 illustrates the effect of the steel fiber contents on the change in the strain at the maximum stress, as indicated by the results of previous studies and by the results of this study. The change in the strain at the maximum stress exhibited a higher correlation to the contents of steel fibers than did the increase with compressive strength of matrix. The results of the experiments conducted in our study are shown in Figure 7 along with the results from previous studies. The test results indicate that, for mixes with design compressive strengths of $80 \mathrm{MPa}, \varepsilon_{c o}$ increases with increasing steel fiber content but, for mixes with strengths of more than $100 \mathrm{MPa}, \varepsilon_{c o}$ decreases with increasing fiber content. This phenomenon was particularly significant for the specimens with design compressive strengths of $200 \mathrm{MPa}$. Normal strength concrete has shown similar change according to the steel fiber inclusion.

3.4. Effect of Steel Fiber Contents on Elastic Modulus of Concrete. Higher compressive strength of concrete is achieved by homogenization of the constituent materials and of their strengths. Accordingly, the elastic modulus of concrete tends to increase with increasing concrete strength. The elastic modulus derived from test results obtained in previous studies and in our study was examined to assess the trend in the elastic modulus of fiber-reinforced reactive powder concrete with respect to the previously defined reinforcing index. Figure 8 shows the distribution of elastic modulus of concrete test results according to the reinforcing index. Because the elastic modulus is affected by the strength and strain simultaneously, the increases in strength and

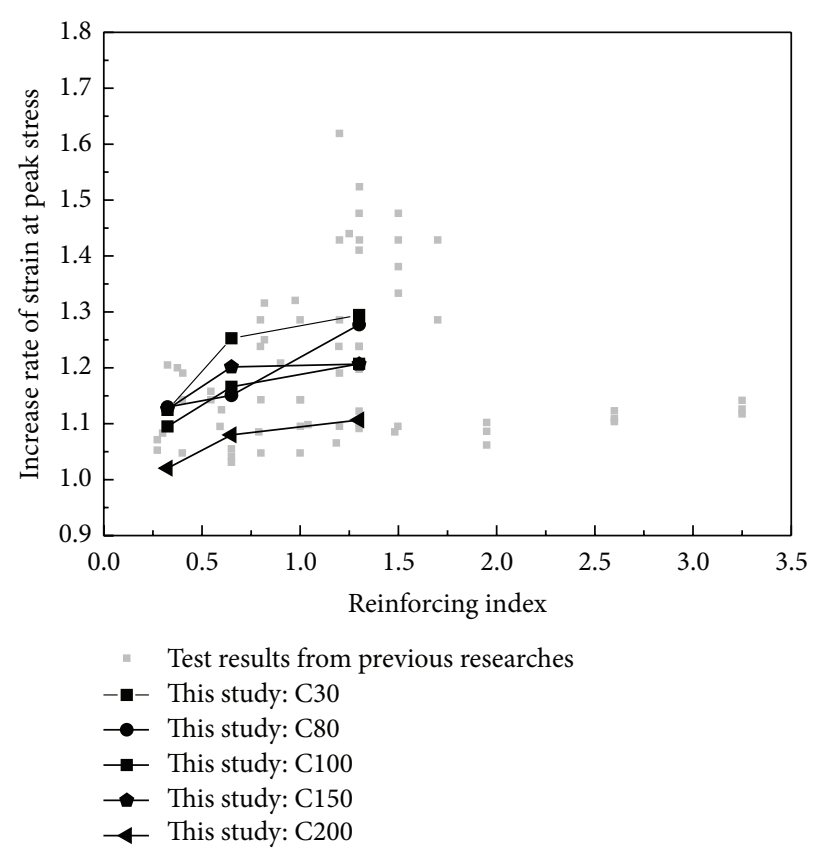

FIGURE 7: Strain at peak stress increase rate according to reinforcing index.

stress exhibit similar trends. The degree to which the elastic modulus increased with the fiber reinforcing index decreased with increasing concrete compressive strength. However, the average increase was $6.5 \%$ which is lesser than that for the strength or strain. Our test results revealed similar trends. Specimens in the C80 test group (with design compressive strengths of $80 \mathrm{MPa}$ ) exhibited the greatest increases among high strength concrete mixes. Specimens in test groups with design compressive strength greater than $100 \mathrm{MPa}$ exhibited smaller increases and trends similar to those observed in the results from previous studies.

\section{Equation for Estimating the Effect of the Steel Fiber Contents on the Mechanical Properties of Steel Fiber-Reinforced Reactive Powder Concrete under Uniaxial Compression}

The effects of steel fiber on concrete strength improvement observed in the test results obtained in this study and in previous studies [30-44] were quantified for compressive strength ranges in increments of $20 \mathrm{MPa}$, as shown in Figure 9. The magnitude of the improvement within each range was determined from linear regression analysis of the data for the specimens within that range. The regression analysis was performed using the model form shown as

$$
\frac{k_{c f}}{k_{c o}}=1+\mathrm{RI} \times \alpha,
$$

where $k_{c f}$ is mechanical properties for steel fiber-reinforced concrete, $k_{c o}$ is mechanical properties on nonreinforced concrete, $\mathrm{RI}$ is reinforcing index, and $\alpha$ is regression coefficient. 


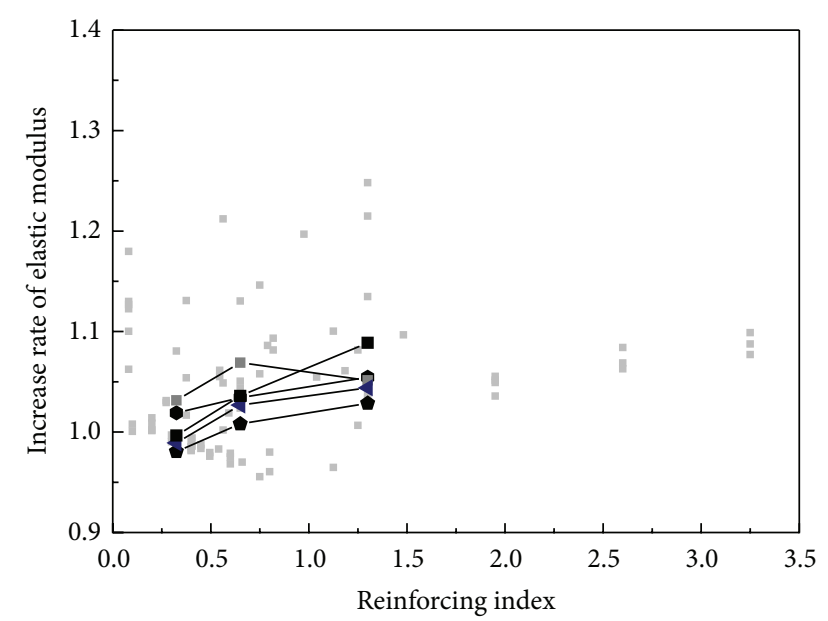

$\quad$ Test results from previous researches
$-\square-$ This study: C30
- - This study: C80
- - This study: C100
- - This study: C150
$-\leftarrow$ This study: C200

FIGURE 8: Elastic modulus increase rate according to reinforcing index.

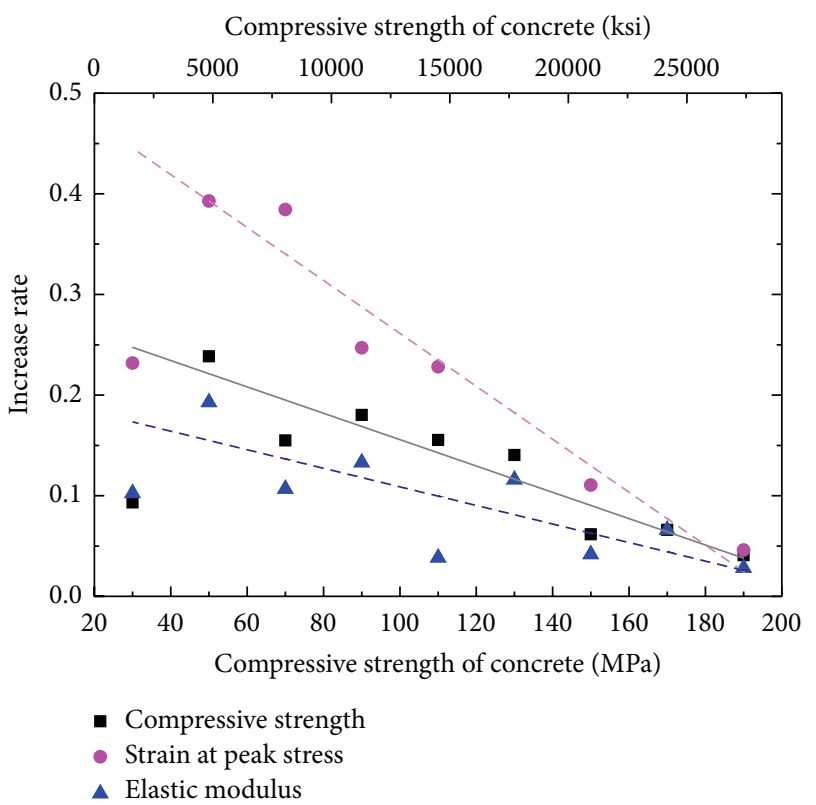

FIGURE 9: Change of statistical values and trend lines on mechanical characteristics of steel fiber-reinforced reactive powder concrete under uniaxial compression.

The increase in compressive strength with inclusion of steel fiber exhibited a clear decreasing trend with increasing concrete compressive strength. The results of the regression analysis suggest that the magnitude of the improvement in the compressive strength, which depends on the elastic modulus, the strain at the maximum stress, and the compressive strength of concrete, can be expressed by

$$
\frac{k_{c f}}{k_{c o}}=1+\operatorname{RI}\left(a_{1}-b_{1} f_{c k}\right) \text {. }
$$

In the above equation, $a_{1}$ and $b_{1}$ are regression coefficients. The values of $a_{1}$ and $b_{1}$ were determined to be 0.29 and 0.0013 , respectively, for change in the compressive strength; 0.52 and 0.0026 , respectively, for change in $\varepsilon_{c o}$; and 0.20 and 0.00092 , respectively, for change in elastic modulus.

In order to verify the applicability of proposed equations predicting mechanical properties of steel fiber-reinforced reactive powder concrete under uniaxial compression, we apply these equations to the stress-strain relation of concrete under uniaxial compression.

Most of the stress-strain relation of concrete are determined by the important mechanical properties, elastic modulus of concrete, and strain at peak stress. Stress-strain relations proposed by previous researches were investigated. There are several types of stress-strain relation of concrete. But in this study, we investigated the way to use the elastic modulus for predicting stress-strain relation of concrete, because stress-strain relations of high strength or ultrahigh strength concrete depend on the elastic modulus as we investigated in this study. The first one of stress-strain relation of concrete we investigated is suggested by Collins et al. [6] and the other is suggested by Attard and Setunge [10]. Collins et al. use the differential of plasticity as base model and Attard and Setunge [10] use the mathematical model to predict stress-strain relationship. Both of them use the elastic modulus of concrete as main variable for prediction of stressstrain relation. However, mathematical model which was suggested by Attard and Setunge [10] needs more boundary conditions such as inflection points after experiencing peak stress. Inflection points of descending curve of stress-strain relation are highly dependent on the experimental equipment. Therefore, in this study, stress-strain relation suggested by Collins et al. [6] is used for prediction of stress-strain relation by using proposed equation of main variables such as elastic modulus and strain at peak stress. The stress-strain relation suggested by Collins et al. [6] can be described using

$$
\frac{f_{c}}{f_{c}^{\prime}}=\frac{n\left(\varepsilon_{c f} / \varepsilon_{c}^{\prime}\right)}{n-1+\left(\varepsilon_{c f} / \varepsilon_{c}^{\prime}\right)^{n k}},
$$

where $f_{c}^{\prime}$ is peak stress obtained from cylinder test, $\varepsilon_{c}^{\prime}$ is strain when $f_{c}$ reaches $f_{c}^{\prime}, n$ is curve fitting factor equal to $E_{c} /\left(E_{c}-\right.$ $\left.E_{c}^{\prime}\right), E_{c}$ is tangent stiffness when $\varepsilon_{c f}$ is zero, $E_{c}^{\prime}$ is secant stiffness when $\varepsilon_{c f}$ is $\varepsilon_{c}^{\prime}$, and $k$ model the strain decay before and after experiencing peak stress. $n$ and $k$ are suggested by using data of high strength concrete and we decided to use these two variables without change. $n$ and $k$ can be calculated by using

$$
\begin{aligned}
& n=0.8+\frac{f_{c}^{\prime}}{17}, \\
& k=0.67+\frac{f_{c}^{\prime}}{62} .
\end{aligned}
$$

For the verification of the applicability of suggested equations, stress-strain relationships of concrete were constructed and compared with experimental results. As can be seen in Figure 10, predicted stress-strain relationship 


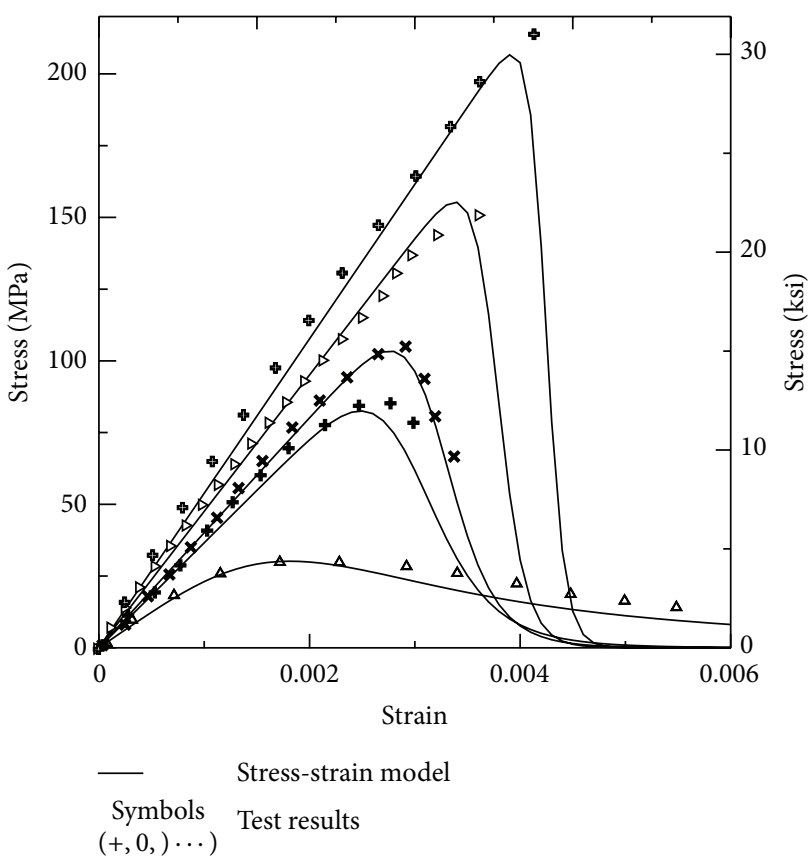

(a) $V_{f}=0 \%$

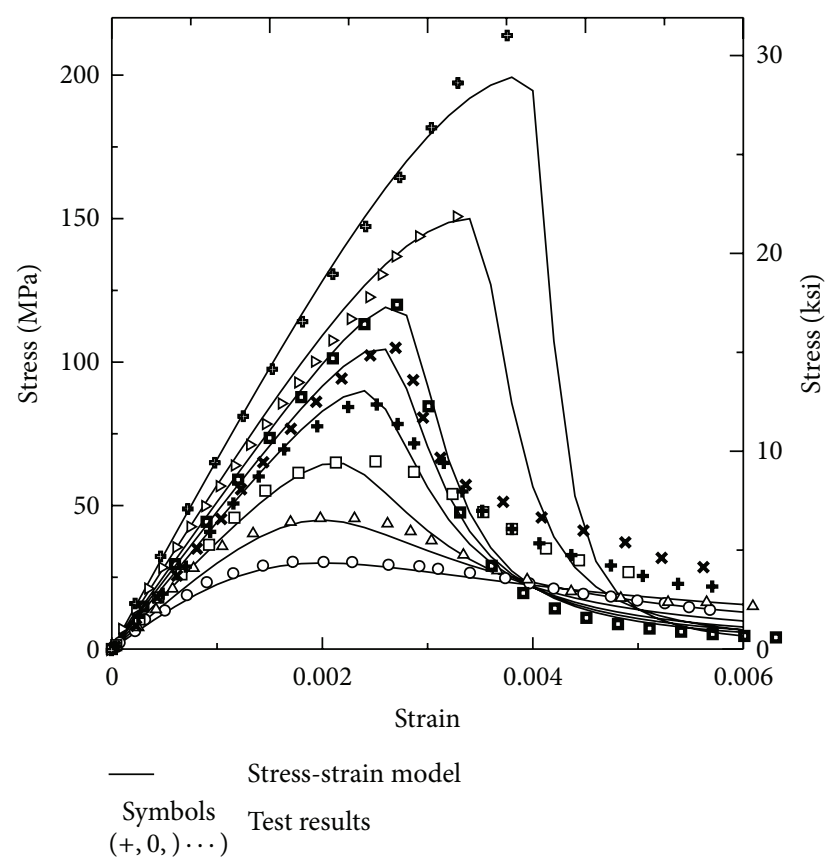

(b) $V_{f}=2.0 \%$

FIgURE 10: Applicability for stress-strain relationship: prediction and experimental results.

of ascending curve was well fitted into the experimental results. However, descending curve of prediction shows less accuracy in descending part of the total stress-strain relation. The inaccuracy of descending curve of stress-strain relation prediction might be caused by the difference of stiffness of experiencing equipment. Making more exact solution, energy absorption capacity under compression shall be investigated.

\section{Conclusion}

In this study, we conducted material testing to evaluate the properties of ultrahigh strength concrete which was made from reactive powder concrete reinforced with steel fibers under compressive loading, and we evaluated the suitability of equations developed in previous studies for use in estimating material properties of ultrahigh strength concrete. The results of this study are summarized as follows.

(1) The compression test results for non-fiber-reinforced and fiber-reinforced ultrahigh strength concrete specimens indicated that non-fiber-reinforced concrete specimens exhibited brittle fractures, whereas fiberreinforced concrete specimens did not. The test results suggest that reinforcing fibers resisted the horizontal tensile forces induced by vertical compressive loading.

(2) The test results confirmed that the effects of steel fiber on the concrete compressive strength, strain at maximum stress, and elastic modulus exhibited linear trends regardless of the compressive strength of the mix. Compressive strength and elastic modulus were not significantly affected by the amount of reinforcing fiber in the mix. However, a relatively strong effect on the strain at the maximum stress was confirmed.

(3) The mechanical properties of the concrete, such as the elastic modulus and the strain at the peak stress, were estimated with a high degree of accuracy using the secant modulus estimation equation presented in the current design standards and by Collins et al.s equation, respectively. Thus, the applicability of these equations to concrete in the ultrahigh strength range was confirmed.

(4) Regression analyses were performed on the test results from this study and previous studies to describe the effects of fiber reinforcement on the material properties of interest. The analysis results showed that the reinforcing effects of steel fiber can be expressed in terms of the fiber reinforcing index.

(5) Analysis of the test results confirmed that the relevant mechanical properties of concrete mix at a given strength level improve in proportion to the fiber reinforcement index. Linear regression analyses were performed for the mechanical properties using equations of the same form for all strength levels. The equation form was chosen so that different values of the regression coefficients were obtained for each strength level.

(6) Proposed equations for mechanical properties under uniaxial compression on concrete can be used as main variables of stress-strain relation. According to comparison, ascending curve of stress-strain relation can be well fitted into experimental results. However, descending part of stress-strain relation 
cannot be well fitted because prediction method did not consider the energy dissipation capacity after experiencing peak stress. In order to construct full range of stress-strain relation of fiber-reinforced concrete, boundary conditions after peak stress shall be considered.

\section{Competing Interests}

The authors declare that there is no conflict of interests regarding the publication of this paper.

\section{Acknowledgments}

This research was supported by Basic Science Research Program through the National Research Foundation of Korea (NRF) funded by the Ministry of Science, ICT \& Future Planning (15CTAP-C097470-01 and NRF-2014R1A1A1005444).

\section{References}

[1] ACI Committee 318, Building Code Requirements for Structural Concrete (ACI 318-11) and Commentary, American Concrete Institute, Farmington Hills, Mich, USA, 2011.

[2] S. Popovics, "A numerical approach to the complete stress-strain curve of concrete," Cement and Concrete Research, vol. 3, no. 5, pp. 583-599, 1973.

[3] M. Sargin, Stress-Strain Relationship for Concrete and the Analysis of Structural Concrete Sections, Study 4, Solid Mechanics Division, University of Waterloo, Waterloo, Canada, 1971.

[4] A. Tomaszewicz, Betongens Arbeidsdiagram, SINTEF, STF65, A84065, Trondheim, 1984.

[5] D. J. Carreira and K.-H. Chu, "Stress-strain relationship for plain concrete in compression," Journal of the American Concrete Institute, vol. 82, no. 6, pp. 797-804, 1985.

[6] M. P. Collins, D. Mitchell, and J. G. MacGregor, "Structural design considerations for high-strength concrete," Concrete International, vol. 15, no. 5, pp. 27-34, 1993.

[7] T. H. Wee, M. S. Chin, and M. A. Mansur, "Stress-strain relationship of high-strength concrete in compression," Journal of Materials in Civil Engineering, vol. 8, no. 2, pp. 70-76, 1996.

[8] P. T. Wang, S. P. Shah, and A. E. Naaman, "Stress-strain curves of normal and lightweight concrete in compression," ACI Journal Proceedings, vol. 75, pp. 603-611, 1978.

[9] Comité Euro-International du Béton-Fédération Internationale de la Précontrainte, "High performance concreterecommended extensions to the model code 90, research needs," CEB Bulletin, no. 228, p. 60, 1995.

[10] M. M. Attard and S. Setunge, "Stress-strain relationship of confined and unconfined concrete," ACI Materials Journal, vol. 93, no. 5, pp. 432-442, 1996.

[11] B. A. Graybeal, "Compressive behavior of ultra-highperformance fiber-reinforced concrete," ACI Materials Journal, vol. 104, no. 2, pp. 146-152, 2007.

[12] A. K. H. Kwan and L. G. Li, "Combined effects of water film thickness and paste film thickness on rheology of mortar," Materials and Structures/Materiaux et Constructions, vol. 45, no. 9, pp. 1359-1374, 2012.
[13] F. de Larrard and T. Sedran, "Optimization of ultra-highperformance concrete by the use of a packing model," Cement and Concrete Research, vol. 24, no. 6, pp. 997-1009, 1994.

[14] L. G. Li and A. K. H. Kwan, "Packing density of concrete mix under dry and wet conditions," Powder Technology, vol. 253, pp. 514-521, 2014.

[15] KS F 2405, Standard Test Method for Compressive Strength of Concrete, Korean Agency for Technology and Standards, 2010.

[16] M. Ros, Material-Technological Foundation and Problems of Reinforced Concrete, Bericht no. 162, Eidgenössische Materialprüfungs- und Versuchsanstalt für Industrie, Bauwesen und Gewerbe, Zurich, Switzerland, 1950.

[17] A. Fafitis and S. P. Shah, "Predictions of ultimate behavior of confined columns subjected to large deformations," Journal of the American Concrete Institute, vol. 82, no. 4, pp. 423-433, 1985.

[18] B. De Nicolo, L. Pani, and E. Pozzo, "Strain of concrete at peak compressive stress for a wide range of compressive strengths," Materials and Structures, vol. 27, no. 4, pp. 206-210, 1994.

[19] European Commitee for Standardization (CEN), Design of Concrete Structures-Part 1-1: General Rules and Rules for Buildings, Eurocode 2, Brussels, Belgium, 2004.

[20] P. Soroushian and C. H. Lee, "Constitutive modeling of steel fiber reinforced concrete under direct tension and compression. fibre reinforced cements and concretes : recent developments," in Proceedings of the International Conference held at the University of Wales, Collige of Cardiff, School of Engineering, United Kingdom, London, UK, September 1989.

[21] M. C. Nataraja, N. Dhang, and A. P. Gupta, "Stress-strain curves for steel-fiber reinforced concrete under compression," Cement and Concrete Composites, vol. 21, no. 5-6, pp. 383-390, 1999.

[22] R. P. Dhakal, C. Wang, and J. B. Mander, "Behavior of steel fibre reinforced concrete in compression," in Proceedings of the Nanjing: International Symposium on Innovation \& Sustainability of Structures in Civil Engineering, 2005.

[23] Korea Concrete Institute, Concrete Design Code and Commentary, Kimoondang Publishing Company, Seoul, Republic of Korea, 2007.

[24] Korea Concrete Institute, Concrete Design Code and Commentary, Kimoondang Publishing Company, Seoul, Korea, 2012.

[25] S. Martinez, A. H. Nilson, and F. Slate, "Spirally reinforced highstrength concrete columns," ACI Journal, vol. 81, no. 5, pp. 431442, 1984.

[26] J. E. Cook, “10,000 PSI concrete," Concrete International: Design and Construction, vol. 11, no. 10, pp. 67-75, 1989.

[27] S. H. Ahmad and S. P. Shah, "Complete triaxial stress-strain curves for concrete," Journal of the Structural Division, vol. 108, no. 4, pp. 728-742, 1982.

[28] J. Gao, W. Sun, and K. Morino, "Mechanical properties of steel fiber-reinforced, high-strength, lightweight concrete," Cement and Concrete Composites, vol. 19, no. 4, pp. 307-313, 1997.

[29] S. K. Padmarajaiah, Influence of fibers on the behavior of high strength concrete in fully/partially prestressed beams: an experimental and analytical study [Ph.D. thesis], Indian Institute of Science, Bangalore, India, 1999.

[30] H.-K. Choi, B.-I. Bae, and C.-S. Choi, "Mechanical characteristics of ultra high strength concrete with steel fiber under uniaxial compressive stress," Journal of the Korea Concrete Institute, vol. 27, no. 5, pp. 521-530, 2015.

[31] S. V. T. J. Perera, H. Mutsuyoshi, and S. Asamoto, "Properties of high-strength concrete," in Proceedings of the 12th International Summer Symposium of Japan Society of Civil Engineers (JSCE '10), Funabashi, Japan, 2010. 
[32] K. F. Sarsam, I. A. S. Al-Shaarbaf, and M. M. S. Ridha, "Experimental investigation of shear-critical reactive powder concrete beams without web reinforcement," Engineering \& Technology Journal, vol. 30, no. 17, pp. 2999-3022, 2012.

[33] D. A. Pandor, Behavior of high strength fiber reinforced concrete beams in shear [M.S. thesis], Massachusetts Institute of Technology, 1994.

[34] J. Thomas and A. Ramaswamy, "Mechanical properties of steel fiber-reinforced concrete," Journal of Materials in Civil Engineering, vol. 19, no. 5, pp. 385-392, 2007.

[35] S. Kang and G. Ryu, "The effect of steel-fiber contents on the compressive stress-strain relation of Ultra High Performance Cementitious Composites (UHPCC)," Journal of the Korea Concrete Institute, vol. 23, no. 1, pp. 67-75, 2011.

[36] P. Bhargava, U. K. Sharma, and S. K. Kaushik, "Compressive stress-strain behavior of small scale steel fibre reinforced high strength concrete cylinders," Journal of Advanced Concrete Technology, vol. 4, no. 1, pp. 109-121, 2006.

[37] Y.-C. Ou, M.-S. Tsai, K.-Y. Liu, and K.-C. Chang, "Compressive behavior of steel-fiber-reinforced concrete with a high reinforcing index," Journal of Materials in Civil Engineering, vol. 24, no. 2, pp. 207-215, 2012.

[38] A. Samer Ezeldin and P. N. Balaguru, "Normal- and highstrength fiber reinforced concrete under compression," Journal of Materials in Civil Engineering, vol. 4, no. 4, pp. 415-429, 1992.

[39] B.-W. Jo, Y.-H. Shon, and Y.-J. Kim, “The evalution of elastic modulus for steel fiber reinforced concrete," Russian Journal of Nondestructive Testing, vol. 37, no. 2, pp. 152-161, 2001.

[40] O. Kazuhiro, S. Shunsuke, A. Hideo et al., An Experimental Study on the Compressive Properties of the Super-High Strength Concrete, vol. 25, Architectural Institute of Japan, China Branch, Research Report Collection, 2002.

[41] A. R. Murthy, N. R. Iyer, and B. K. R. Prasad, "Evaluation of mechanical properties for high strength and ultrahigh strength concretes," Advances in Concrete Construction, vol. 1, no. 4, pp. 341-358, 2013.

[42] N. N. Meleka, A. A. Bashandy, and M. A. Arab, "Ultra high strength concrete using economical materials," International Journal of Current Engineering and Technology, vol. 3, no. 2, pp. 393-402, 2013.

[43] D. Moldovan and C. Măgureanu, "Stress-strain diagram for high strength concrete elements in flexure," in Proceedings of the 3rd International Conference Advanced Composite Materials Engineering (COMAT '10), pp. 137-142, Transilvania University Press of Brasov, Brasov, Romania, 2010.

[44] W. I. Khalil and Y. R. Tayfur, "Flexural strength of fibrous ultra high performance reinforced concrete beams," ARPN Journal of Engineering and Applied Sciences, vol. 8, no. 3, pp. 200-214, 2013.

[45] R. Narayanan and I. Y. S. Darwish, "Use of steel fibers as shear reinforcement," ACI Structural Journal, vol. 84, no. 3, pp. 216227, 1987. 

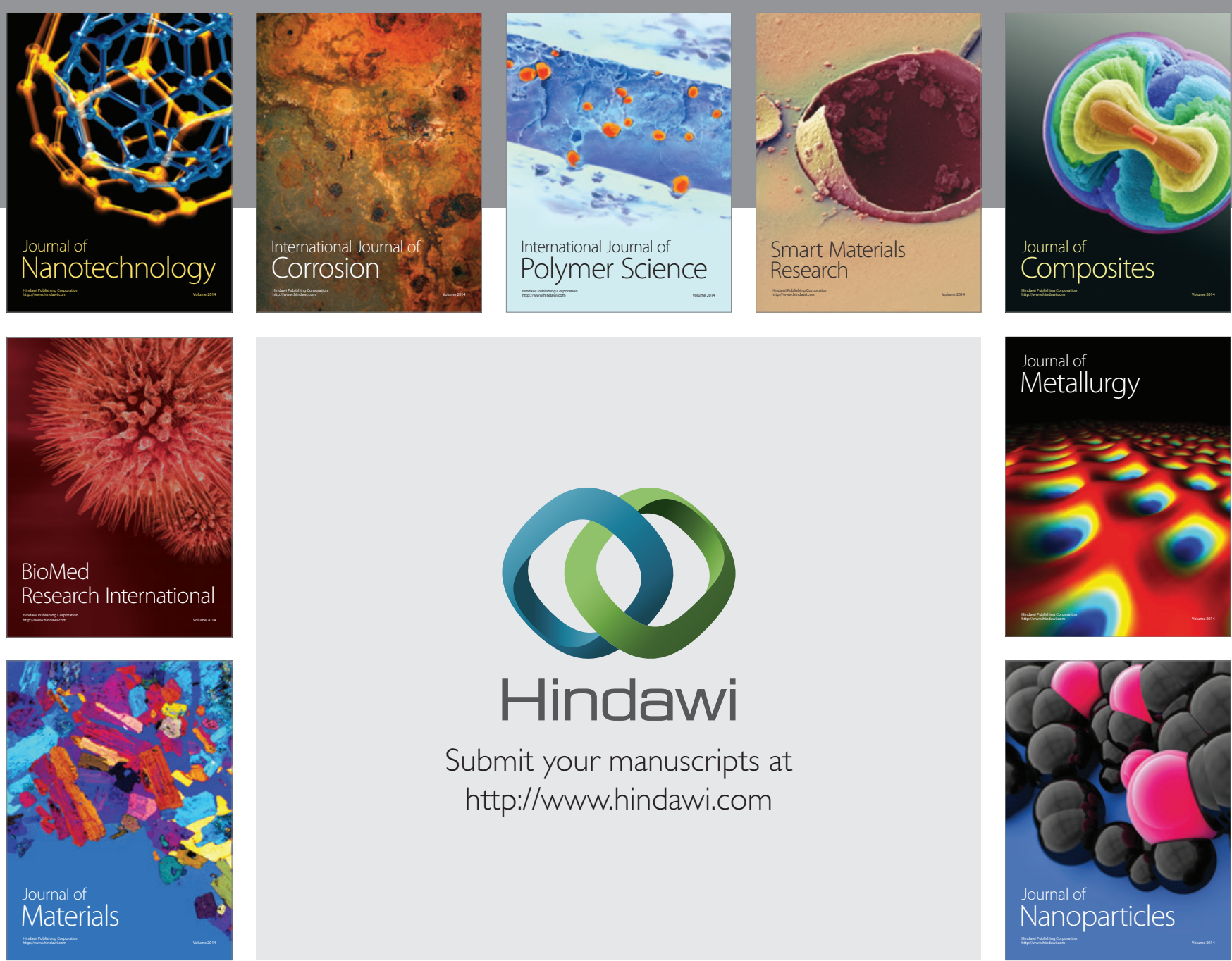

\section{Hindawi}

Submit your manuscripts at

http://www.hindawi.com

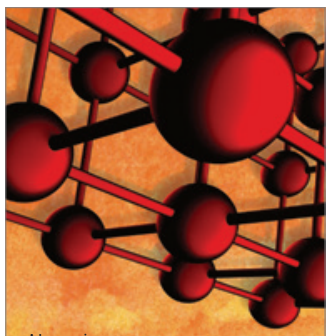

Materials Science and Engineering
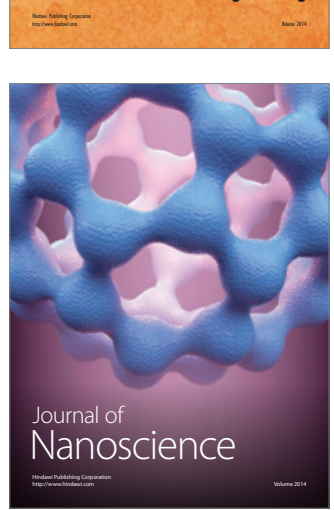
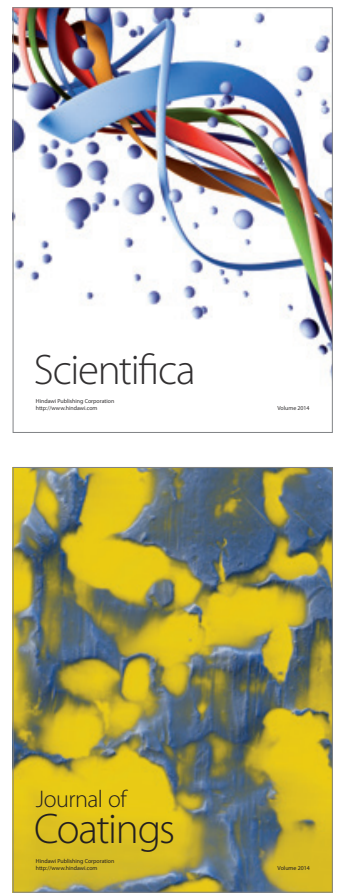
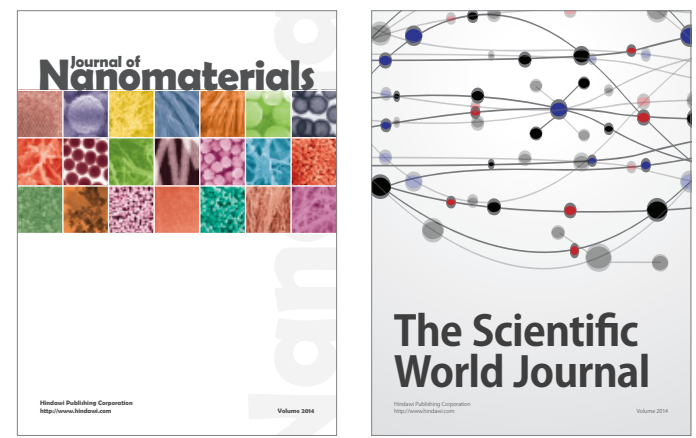

The Scientific World Journal
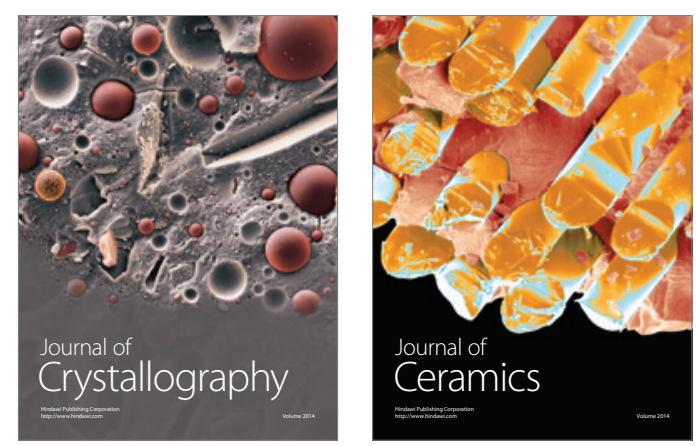
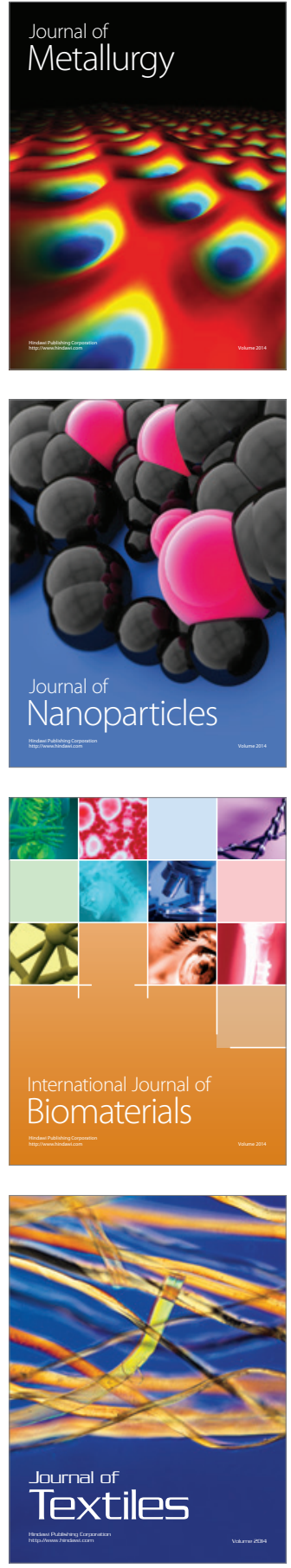